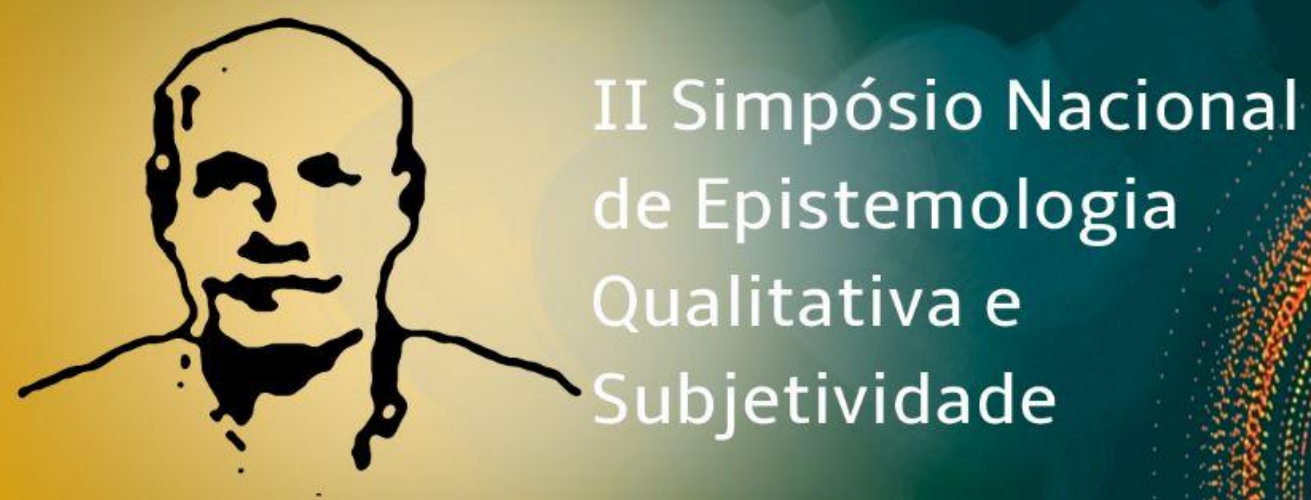

Eixo temático: A dimensão subjetiva da deficiência no processo de inclusão escolar

\title{
A EXPRESSÃO DA CRIATIVIDADE NO ENSINO DA LIBRAS NO ATENDIMENTO EDUCACIONAL ESPECIALIZADO
}

Aldeci Fernandes da Cunha/UERN. E-mail: aldecyfernandes@ hotmail.com.

\section{Resumo}

Este trabalho apresenta uma discussão sobre criatividade como uma expressão da subjetividade e da produção humana. É um estudo realizado em uma escola da rede estadual de ensino da cidade de Assú/RN-Brasil, tendo como objetivo identificar a ocorrência de estratégias criativas no ensino da Libras ofertado pelo Atendimento Educacional Especializado. A compreensão teórica adotada no estudo é definida epistemologicamente no conceito de Criatividade, construído por Mitjáns Martinez (1997) a partir da teoria da Subjetividade desenvolvida por González Rey, numa perspectiva histórico-cultural da subjetividade. O caminho metodológico adotado assume os princípios da Epistemologia Qualitativa (GONZÁLEZ REY, 2010), a qual se articula com os estudos da subjetividade. A pesquisa foi realizada no ambiente da sala de recurso multifuncional, espaço de realização do atendimento educacional especializado (AEE), junto aos profissionais responsáveis pelo atendimento educacional ao aluno com surdez que frequentam o AEE. Para análise e construção das informações utilizamos conversas informais e, o Plano de atendimento do AEE. Com a pesquisa, percebemos que a trajetória de vida dos profissionais envolvidos com e no AEE, contribui para com a construção de caminhos didáticos e metodológicos que contribuem para com a inclusão do aluno com deficiência no espaço do AEE e na sala de aula do ensino regular. O estudo revela, portanto, que a realização de uma prática criativa e inclusiva, se constrói a partir do processo relacional do professor consigo e com os outros, e, de sua compreensão construída em sua história de vida nas dimensões individual, social e cultural.

Palavras-chave: Criatividade. Subjetividade. Inclusão

\section{Tecendo saberes teórico-metodológico para a construção de uma escola inclusiva}

Tecer uma prática pedagógica numa escola inclusiva nos remete a reflexão da necessidade de pensar um fazer docente capaz de construir estratégias didático-pedagógicas, que possibilite a inclusão do aluno com deficiência nos cotidianos escolares e sociais. Assim, compreendemos que a escola inclusiva, é a escola que a todo tempo cria caminhos e 


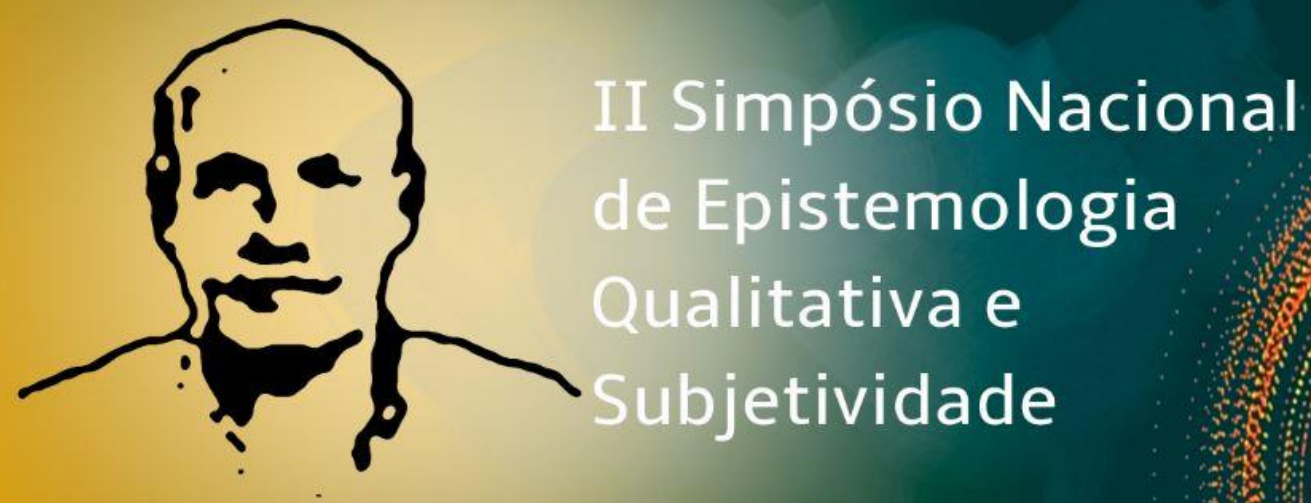

aprendizagem e na inclusão do aluno surdo no espaço escolar e social. Isso, nos possibilita compreender que, mesmo existindo algumas ausências e emergências no Ensino da Libras, no AEE, a ação desenvolvida pelo professor possui elementos de uma ação criativa.

Também encontramos nessa parte do registro, o professor/instrutor falando de atividades criativas, justamente o que ele acredita ser "criatividade" na prática docente: atividades que facilitem a aprendizagem.

Não nos referimos aqui, quando falamos da aprendizagem, aos conteúdos trabalhados na sala de aula regular de ensino, onde o ensino da Libras desenvolvido no AEE é desarticulado com o que é discutido na sala regular. Identificamos que a aprendizagem concebida por parte do professor e do instrutor é o processo de alfabetização em L1 e em L2 escrita, acreditando que se alfabetizando na L1 e na L2 haverá contribuição para a inclusão escolar e social do aluno surdo.

Outro elemento que compõe o Plano do AEE caracteriza-se como Resolução do Problema, no qual, a partir do diagnóstico do aluno, o professor/instrutor apresenta algumas estratégias utilizadas no atendimento, o que consideramos como um elemento que contém indicadores para nossa reflexão construtiva e interpretativa.

\section{Resolução do Problema}

Usar jogos variados no computador, leituras de imagens, alfabeto em Libras, jogos em Libras, conversas informais utilizando Libras.

O registro dos profissionais acerca da Resolução do Problema nos remete a identificar a ausência de algumas informações mais consistentes, dentre elas podemos destacar, a compreensão do professor frente ao diagnóstico do aluno, que é um conhecimento mais teórico sobre a aprendizagem do aluno surdo, além do conhecimento acerca da confecção de materiais didáticos para a prática docente a ser desenvolvida no AEE em Libras.

Ressaltamos que sentimos a ausência dos problemas existentes em relação ao atendimento do aluno no registro do professor, já que nessa parte do Plano devem ser discutidas de como trabalhar pedagogicamente os problemas encontrados.

Dessa forma, analisamos que existe na ação didática dos profissionais a compreensão da necessidade de estabelecer caminhos para facilitar ou contribuir com a aprendizagem do aluno com surdez, o que nos leva a refletir sobre a existência de uma ação em que os responsáveis pelo AEE em Libras procuram se alinhar de forma que o aluno tenha interesse 


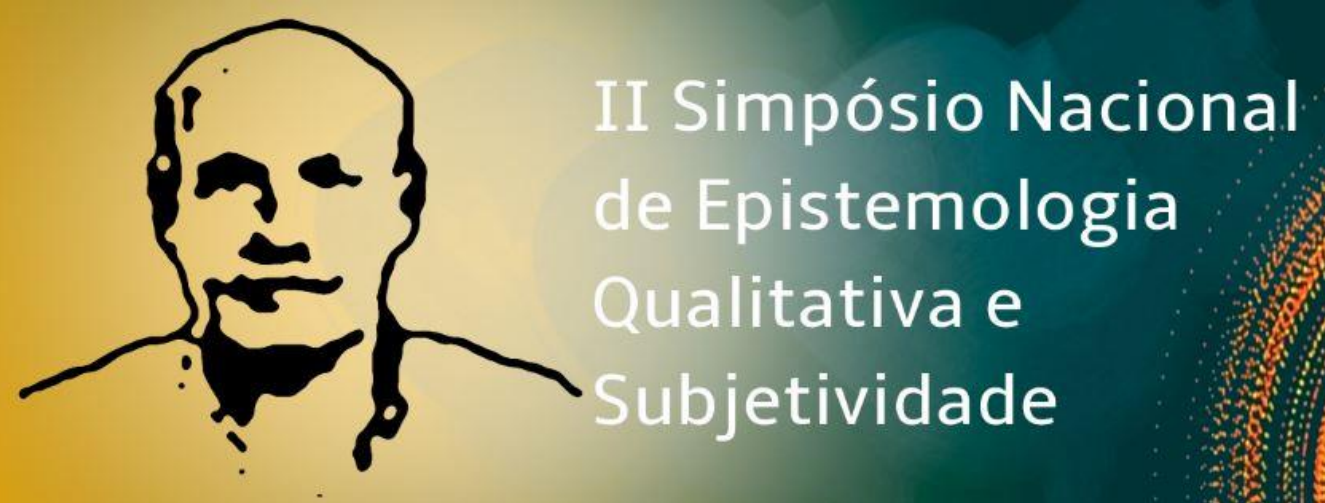

cognitivos, seja no que se refere à aquisição da L1 e da L2 na modalidade escrita. Encontramos aqui elementos que consideramos como favorecedores da expressão criativa no profissional, pois a atividade criativa é aquela que ultrapassa a dimensão tradicional, ainda muito presente na sala de aula, marcada pela aula expositiva com o uso de quadro e giz.

Nessa perspectiva, trazemos outro elemento do Plano de atendimento, denominado de "Atividades a serem desenvolvidas no atendimento do aluno", em que o professor apresenta uma série de atividades, que trazem indicadores que contribuem para com as nossas reflexões acerca de presença de elementos criativos ou não no espaço de atendimento realizado na sala de SRM, com alunos surdos, durante a realização do AEE em Libras.

Atividades a serem desenvolvidas no atendimento do aluno

Jogos educativos no computador;

Jogos de memória, quebra-cabeça;

Atividades com recorte e colagem;

Sequência lógica;

Jogos em Libras (dominó, loto Libras e outras);

Caça-palavras (português e Libras);

Gravuras.

De acordo com os registros, percebemos traços de uma prática lúdica, onde o AEE é realizado por uma diversidade de estratégias, o que torna o atendimento um espaço de ludicidade, permitindo o envolvimento do aluno na ação didática realizada no ambiente da SRM.

Nas informações apresentadas na listagem das atividades a serem desenvolvidas no, percebemos que existe uma prática criativa, pois a partir de objetivos, os alunos conseguem aprender o que é proposto. A prioridade do atendimento - percebido nas conversas informais - é a alfabetização em Libras.

Ainda encontramos no Plano do AEE o item "Seleção de materiais a serem confeccionados para o aluno", o qual apresenta elementos que complementam e vão ao encontro do que estamos discutindo, conforme abaixo apresentado.

Seleção de materiais a serem confeccionados para o aluno

Cartazes (Libras);

Atividades em Libras (variadas);

Construção de jogos da memória.

Nessa parte do Plano, identificamos que os materiais produzidos pelo professor contribuem para a realização do atendimento e demonstram o uso do material lúdico e visual 
